\title{
Levofloxacin: Insights Into Antibiotic Resistance and Product Quality
}

\author{
Ensieh Izadi ${ }^{1}$, Gull Afshan ${ }^{2}$, Rahul P. Patel', Venkatesan M. Rao ${ }^{3}$, Kai Bin Liew ${ }^{4}$, \\ Meor Mohd Redzuan Meor Mohd Affandi ${ }^{5}$, Nurolaini Kifli ${ }^{6}$, Amal Suleiman ${ }^{7}$, \\ Kah Seng Lee ${ }^{4}$, Md. Moklesur R. Sarker ${ }^{8}$, Syed Tabish Zaidi ${ }^{1,9}$ and Long Chiau Ming ${ }^{1,6}$ \\ ${ }^{1}$ Division of Pharmacy, School of Medicine, University of Tasmania, Hobart, TAS, Australia, ${ }^{2}$ Department of Pulmonary \\ Medicine, Liaquat National Hospital and Medical College, Karachi, Pakistan, ${ }^{3}$ Faculty of Pharmacy, SEGi University, \\ Kota Damansara, Malaysia, ${ }^{4}$ Faculty of Pharmacy, Cyberjaya University College of Medical Sciences, Cyberjaya, Malaysia, \\ ${ }^{5}$ Faculty of Pharmacy, Universiti Teknologi MARA, Puncak Alam, Malaysia, ${ }^{6}$ PAPRSB Institute of Health Sciences, Universiti \\ Brunei Darussalam, Gadong, Brunei Darussalam, ${ }^{7}$ College of Pharmacy, Prince Sattam Bin Abdulaziz University, Al Kharj, \\ Saudi Arabia, ${ }^{8}$ Department of Pharmacy, State University of Bangladesh, Dhaka, Bangladesh, ${ }^{9}$ School of Healthcare, \\ University of Leeds, Leeds, United Kingdom
}

Counterfeit and substandard medicines are recognized as one of serious threats to public health. The product quality of antibacterial medicine will compromise patients' recovery and increase the chance of antibacterial resistance. The review aims to provide a summary of low quality levofloxacin issues and the risk factors as well as suggesting the aspects of product quality that need to be regulated strictly. Quality of the active ingredient, levofloxacin, has an important role to contribute to successful therapy. The poor quality of raw material, directly and indirectly, causes treatment failure as the presence of insufficient dose, mislabeled content, and poor dissolution characteristics can lead to lower bioavailability. Identifying and reporting these factors can potentially help in improving the quality of drug marketed in various developing countries and may also reduce the incidences of treatment failure. Dissolution test is used for testing the dissolution profiles and the rate of drug release from solid formulation such as oral formulations, thus providing information regarding the in vivo performance of a formulation and its bioequivalence. On the other hand, quality-testing procedures are used for comparing the quality of products.

Keywords: counterfeit, post marketing surveillance, regulatory requirement, fluroquinolone resistance, quality medicine

\section{INTRODUCTION}

Nowadays, treatment failure of infectious diseases is one of the major healthcare issues especially in developing countries (Lee et al., 2015). Respiratory tract infection (RTI) is one of the main microbial infections in developing countries that causes about 4-5 million deaths per year among children (Liu et al., 2014). For instance, pneumonia is an inflammation of air sacs in lungs and one of common RTI that may cause hospitalization and mortality (Lee et al., 2015; Crispian, 2016). Although the emergence of antibiotic therapy and vaccines in the twentieth century increased the survival rate among these patients, however, it was still reported that pneumonia caused a high incidence of death rate among geriatrics and children especially in the developing countries (Basnet et al., 2015). There are resistance cases reported on first-line 
antibiotics such as penicillin and macrolides for the treatment of pneumonia. Quinolone class is considered as one of the empirical treatments of the infection (Endimiani et al., 2005). However, the rising of quinolone resistance cases is alarming in North and South American countries in the year 2000 (Kays et al., 2002). Haemophilus influenzae is one of common organisms which can cause RTI, and there are few studies reported the quinolone-resistant of $H$. influenzae (Bastida et al., 2003). There are few studies suggesting that poor quality and substandard drugs are a major contributor to antibiotic resistance in RTIs in developing countries (Conway et al., 2013; Currie et al., 2014; Basnet et al., 2015). This draws the attention of regulatory authority to look into the aspect of poor quality medicines which were reported in many developing countries. It is reported that a significant percentage of generic drugs fails to meet the innovator specifications in Latin America (Nightingale, 2005).

Drug quality has a key role to deliver successful treatments. It is important to achieve the required minimum inhibitory concentration (MIC) in order to cure an infection (Miller et al., 2005). High quality antibiotics are essential in treatment of serious common RTIs while poor quality antibiotic therapy may increase morbidity and mortality rates (Khasawneh et al., 2014). Hence, the aim of this review is to summarize low quality levofloxacin tablet issue and suggest aspects of product quality that need to be strengthen and regulated strictly.

\section{LEVOFLOXACIN RESISTANCE}

Previous studies conducted in South Korea, Canada, USA, and Spain show the correlation between fluoroquinolone administration and resistance (Kays et al., 2002). The resistance of microbes toward some fluoroquinolones products have been reported in the treatment of hospital acquired infections (Torloni et al., 2016). Kays et al. (2002) have claimed that levofloxacin susceptibility in pneumonia infection had reduced as utilization of levofloxacin prescription increased. Meanwhile, Davidson et al. (2002) reported treatment failure in Streptococcus pneumoniae in three different cases after fluoroquinolone administration. Fluoroquinolone resistance is reported in some developing countries such as China and Thailand with $3 \%$ non-susceptibility to levofloxacin while the fluoroquinolone resistance against S. pneumonia is below $1 \%$ in the United States from 1987 to 1998 (Sahm et al., 2000; Hu et al., 2011). Although, the results in the United States may be related to different prescribing behaviors or fundamental characteristics of the selected pathogens, but S. pneumonia is still capable of resistance development in fluoroquinolone therapy (Sahm et al., 2000; Davidson et al., 2002). Seok et al. (2018) have stated evidence for non-susceptibility to levofloxacin due to prior usage of antibiotics within 3 months, and it is recommended to restrict unnecessary fluoroquinolone prescriptions. Also, Ayukekbong et al. (2017) have presented multiple factors contributing to the problem of antimicrobial resistance due to unnecessary antibiotic prescriptions, especially in developing countries. Available evidence suggests that non-susceptibility to levofloxacin is an ongoing problem.

\section{POOR QUALITY DRUG PRODUCTS}

Poor quality drug product is a major global healthcare issues (Sarpong and Miller, 2014). There are studies suggesting that antibacterial drugs mainly antimalarial, antiviral, and antibiotics are among the poor quality drug products reported in developing countries (Nsimba, 2008; Melo et al., 2014). Poor quality drug product is defined as drug product which the drug content does not follow the provided standards such as chemical stability, bioavailability, and purity in drugs (Almuzaini et al., 2013). Poor quality drug product can be subclassified into substandard drugs product and counterfeit drug product (Newton et al., 2010). Substandard drug products are medicines produced by an authorized manufacturer which do not follow designated standard quality standings. On the other hand, counterfeit medicines are defined as "deliberately and fraudulently mislabeled with respect to identity and/or source" whether with the right or falsified ingredients or with the forged labeling. Substandard/counterfeit medicines are not usually bioequivalent due to differences in bioavailability as a result of pharmacokinetics (Johansson et al., 2010).

Moreover, some poor quality drugs do not have good in vivo dissolution in the gastrointestinal tract leading to incomplete absorption; hence, therapeutic levels in blood cannot be achieved (Johansson et al., 2010). The MIC is not achieved when the drug plasma concentration is below expectation which leads to therapy failure and antibiotic resistance (Almuzaini et al., 2013).

Table 1 shows the relevant studies which reported the substandard/counterfeit drugs. These studies claim that there are many substandard or counterfeit drugs available in developing counties (Nightingale, 2005; Hosseini et al., 2011; Bate et al., 2013; Khurelbat et al., 2014; Lalani et al., 2015).

TABLE 1 | The percentage of substandard, counterfeit, and unregistered levofloxacin available in the market of different countries.

\begin{tabular}{lccl}
\hline Regions & $\begin{array}{c}\text { Substandard/ } \\
\text { counterfeit } \\
\mathbf{( \% )}\end{array}$ & $\begin{array}{c}\text { Total } \\
\text { samples }\end{array}$ & References \\
\hline Africa & 16.6 & & \\
India & 10.1 & $713^{*}$ & (Bate et al., 2013) \\
Middle income & 3.9 & & \\
countries & & & \\
Iran & 9.1 & 7910 & (Hosseini et al., 2011) \\
Mongolia & 18 & 388 & (Khurelbat et al., 2014) \\
Afghanistan & 26 & 126 & (Lalani et al., 2015) \\
13 countries & 20 & 40 & (Nightingale, 2005) \\
including Asia and & & & \\
Latin America & & &
\end{tabular}

*The studies were conducted in different countries such as Angola, Brazil, China, Democratic Republic of Congo, Egypt, Ethiopia, Ghana, India, Kenya, Nigeria, Russia, Rwanda, Thailand, Turkey, Uganda, and United Republics of Tanzania and Zambia. 
In addition, many studies have confirmed that substandard or counterfeit drugs caused side effects such as allergies because of impurity, toxicity, or a high percentage of the active agent (Tipke et al., 2008; Wang et al., 2015). Substandard drugs may lead to potential side effects and death as the higher or lower amount of drug than the labeled one is delivered (Boyd et al., 2009; Tamargo et al., 2015; Wang et al., 2015).

\section{ASPECTS OF PRODUCT QUALITY}

It is important that the generic pharmaceutical manufacturers ensure the production of quality products which help to reduce the therapy failure and antibiotic resistance. Several aspects of product quality is discussed in this review-namely, dissolution study and bioequivalence, quality control of product, quality control test and stability of drug product, post-marketing surveillance (PMS), effect of storage, and poor quality control during manufacturing.

\section{DISSOLUTION STUDY AND BIOEQUIVALENCE}

A generic drug is defined as a product which has the same active ingredients as the innovator medicine but with different inactive agents or excipients (Nitzki-George, 2004). Generic drug products are cheaper than the innovator drug products due to the initial saving of research and development expenses for new drugs, so they are highly preferred in the society especially by low income patients (Dunne et al., 2013).

One of the ways to show drug quality of generic product is through bioequivalence study. Bioequivalence study is required to ensure that the generic medicine product is equivalent with the innovator medicine product in terms of pharmacokinetics requirement as maximal serum concentration and area under the curve (drug concentration against time) (Johansson et al., 2010). Hence, FDA uses a bioequivalent approach to assess generic drugs (Paveliu et al., 2011). A bioequivalent is considered if the two drugs in comparison have less than $20 \%$ difference in the pharmacokinetics parameters (Paveliu et al., 2011). Thus, generic drug manufacturers are required to prove that rate and extent of drug absorption into the bloodstream is comparable to the amount from a brand name product (Davit et al., 2009).

Although, both generic and innovator drugs are susceptible to be falsified, but generic medications are easier to be manipulated (Gibson, 2005). In most cases, samples of generic drugs are as safe and effective as branded one, but still some problems may occur (Kesselheim et al., 2008). Treatment failures have been reported in different cases, such that in one case, symptoms were improved after replacing the prescribed generic levofloxacin with Tavanic (Innovator product) without the presence of any adverse effect (Gallelli et al., 2013). The issue was identified as the excipients of the generic product is different (Tamargo et al., 2015). Although the active content that helps to control may be the same, the filler material, color, or binder used may be different (Tamargo et al., 2015). The problem may occur when the active agent is not sufficient or the inactive content has impurity or contamination that can have a great impact on bioavailability, metabolism, and elimination (Tamargo et al., 2015).

\section{QUALITY CONTROL AND STABILITY OF DRUG PRODUCT}

Pharmaceutical industries need to adhere and comply with the good manufacturing practice (GMP) to guarantee the products safety, efficacy, and quality (Li et al., 2015). Nowadays, export or occasional drug use among the country of production is also subjected to compliance with GMP requirements and regulations by manufacturer (Abdellah et al., 2015). Compliance with the requirements and regulation of GMP is considered as an essential and vital aim for quality assurance and ultimately the profitability of the pharmaceutical industry (Tomic et al., 2010).

Analysis of raw materials, substances, and intermediate products are important tasks in pharmaceutical manufacturing and quality control. Pharmacopeia is used as a reference for chemical, physical, and microbiological tests (Kaul et al., 2016). The manufacturers are responsible to not just produce a final product, but they are also obliged to look into the postproduction drug product stability issues (Lambert and Conway, 2003; Wang et al., 2015; Kaul et al., 2016). U.S. Pharmacopeia (USP) is one of commonly available pharmacopeia to control quality of raw materials, components, packaging, and final products (Panchagnula et al., 2006; Kaul et al., 2016).

Innovator (brand name) and generic medicines use the same API, but they may contain diverse inactive agents while they still need to follow quality standards of innovator drug ( $\mathrm{Al}$ Ameri et al., 2012). Quality control is essential for detecting the substandard drugs containing inactive substance, impurities, and toxic substances (Almuzaini et al., 2013; Fadeyi et al., 2015). Substandard drugs can be detected using the quality-testing protocols such as USP which is also defined by the World Health Organization and International Pharmacopeias (Kayumba et al., 2004; Maezawa et al., 2013).

The drug product should contain an equal amount of active pharmaceutical ingredient (API) as stated in the product claim (Zaid et al., 2013). According to WHO's definition, an API is a material or combination of materials that are used in the pharmaceutical products as an active compound with a direct effect in treatment (World Health Organization, 2011; World Health Organization, 2016). The compatibility between API and excipients is important to ensure stability of the API in the dosage form. A stable API will deliver the claimed effect within the shelf life of the product. A crucial role of excipient in drug formulation requires the regulatory approval to avoid toxic or poor quality medicines that may lead to treatment failure (Baldrick, 2000).

\section{Effect of Storage Conditions on Drug Stability}

Storage is one factor that may affect the quality of a drug (Kayumba et al., 2004). The storage under tropical conditions 
was reported by Kayumba et al. (2004) as the main problem of the instability of some formulations of drugs collected in Tanzania, and it was suggested to drug regulatory authorities to develop a quality assurance system to control poor quality drugs. Another study by Nogueira et al. (2011) claims that storage has an essential role in the stability of the drug after production, and poor drug samples were found in poor drug storage conditions in $75 \%$ relative humidity and $40^{\circ} \mathrm{C}$.

\section{Poor Quality Control During Manufacturing}

Quality control framework based on established pharmacopeia techniques is essential to ensure product quality (LosadaUrzáiz et al., 2015). Moreover, lack of quality control due to irresponsibility and corruption increase the percentage of supplying counterfeit drugs in the market which lead to serious public health issues (Zavras et al., 2016). One of the main reasons for quality problems in developing or low income countries is lack of PMS and regulation (Taylor et al., 2001). The financial issue may increase the percentage of treatment failure and resistance due to poor quality or counterfeit drugs in developing countries (Taylor et al., 2001; Nsimba, 2008). Nevertheless, the number of cases of substandard or poor quality drugs are significant in low income and developing countries which can be related to limited financial support in health care, PMS, and pharmaceutical manufacturing (Taylor et al., 2001; Tipke et al., 2008; Conway et al., 2013; Karunamoorthi, 2014; Fadeyi et al., 2015).

\section{Control Measures to Reduce Low Quality Drugs}

Low quality medicine produced during pharmaceutical manufacturing can be detected using drug dissolution studies (Wang et al., 2015). The most effective way to reduce the low quality drugs in the market is strictly prohibiting entry of counterfeit drugs into the market (Losada-Urzáiz et al., 2015). The other way to ensure both innovator and generic drugs are following standards and regulations is clearly expressed to the manufacturers that the specific pharmacopoeial techniques need to be complied (Losada-Urzáiz et al., 2015). Bioequivalence study is a must to ensure that the generic product is equivalent with the innovator product.

\section{CASE STUDY: LEVOFLOXACIN}

Levofloxacin is a broad spectrum antibiotic which belongs to the third generation of quinolones group (Scoper, 2008). It prevents DNA replication in bacteria leading to bacterial cell death, and it is mainly used as a second-line therapy of lungs infection (Noreddin and Elkhatib, 2010). This drug is considered as an important antibiotic in case of microorganism that is resistant to other class of antibacterial agents such as beta-lactam antibiotics; hence, its quality is critical in effective treatment (Kayumba et al., 2004; Endimiani et al., 2005).
Levofloxacin is chosen as the model drug for a common empirical treatment of pneumonia caused by Gram-negative bacteria such as H. influenza as well as Gram-positive bacteria such as S. pneumoniae (Kays et al., 2002).

Levofloxacin has high oral bioavailability with rapid bactericidal activity; hence, it is considered for the treatment of choice for severe pneumonia (Boyd et al., 2009; Maezawa et al., 2013). Although, levofloxacin is one of the most widely prescribed agents for the pneumonia treatment but the number of treatment failure incidences have been recently increased with levofloxacin therapy (Kays et al., 2002; Bastida et al., 2003; Endimiani et al., 2005; Boyd et al., 2009). The possible risk factors suggested for the treatment failure of levofloxacin are poor quality medicines and drug resistance (Davidson et al., 2002). Death in pneumonia due to levofloxacin treatment failure has been reported in North America as four patients in Canada and one patient in the USA in 2000-2001 (Davidson et al., 2002; Kays et al., 2002). Pneumonia can be caused by virus, bacteria, or fungi, and it is commonly categorized as community-acquired pneumonia (CAP) and hospital-acquired pneumonia (HAP) (Abrahamian et al., 2008). The CAP is caused by Streptococcus pneumoniae, Haemophilus influenzae, Chlamydia pneumoniae, and respiratory viruses (Abrahamian et al., 2008; Johansson et al., 2010). On the other hand, HAP occurs after $48 \mathrm{~h}$ of hospital admission by Escherichia coli, Klebsiella pneumoniae, Pseudomonas aeruginosa, and Staphylococcus aureus, including methicillin-resistant $S$. aureus (MRSA) (Imran et al., 2016). The treatment is chosen on the basis of different categories and the causative organisms (Imran et al., 2016). The main treatment of pneumonia is antibiotics while sometimes the patients need to be admitted to the hospital to monitor their progression (Bradley et al., 2014). In addition, approving a specific microbial etiology is important in empirical treatment of pneumonia to minimize the risk of exposed side effects and antibiotic resistance (Leekha et al., 2011). There are different types of antibiotics used for treatment of pneumonia especially in CAP which is the most common pneumonia and may cause serious infections globally (Abrahamian et al., 2008). Although, the particular antibiotic for management of CAP is given based on severity of infections or etiology (pathology) while combination of beta-lactam (amoxicillin) and macrolides (azithromycin) or antipneumococcal fluoroquinolone are the preferred empirical treatment (Mandell et al., 2007).

TABLE 2 | Features of treatment failure of pneumonia due to levofloxacinresistant in different countries.

\begin{tabular}{lll}
\hline $\begin{array}{l}\text { Disease-causing } \\
\text { bacteria }\end{array}$ & Reported country & References \\
\hline Haemophilus influenzae & Spain & \\
Staphylococcus aureus & Pakistan & (Bastida et al., 2003) \\
Streptococcus & Canada & (Rizvi et al., 2014) \\
pneumoniae & (taly & (Davidson et al., 2002) \\
& USA & (Endimiani et al., 2005) \\
& Hong Kong et al., 2002) \\
& & (Ho et al., 2001)
\end{tabular}


TABLE 3 | Various dissolution studies of levofloxacin tablets conducted in various countries.

\begin{tabular}{|c|c|c|c|c|}
\hline Studied country & $\begin{array}{l}\text { Dissolution test setting [speed } \\
(\mathrm{rpm}) / \text { media volume }(\mathrm{ml})]\end{array}$ & Samples tested (numbers) & $\begin{array}{l}\text { Difference in dissolution } \\
\text { profiles }\end{array}$ & Authors \\
\hline Taiwan & $50 / 900$ & 4 & Yes & (Sun et al., 2016) \\
\hline Japan & $50 / 900$ & 24 & Yes & (Maezawa et al., 2013) \\
\hline Pakistan & $50 / 900$ & 6 & No & (Bano et al., 2011) \\
\hline Pakistan & $75 / 1,000$ & 3 & Yes & (Nazir et al., 2013) \\
\hline India & $100 / 900$ & 3 & Yes & (Bhavanam et al., 2011) \\
\hline
\end{tabular}

Therapeutic window is the range between the amount of the drug that gives the desired effect and the drug may be ineffective or toxic if the drug therapeutic index is below or above the range, respectively (Tamargo et al., 2015). Treatment failure may occur by various factors such as an inadequate antibiotic coverage and concentration, deficient diagnosis, or resistance (Sánchez García, 2009). Poor quality antibacterial may lead to drug resistance or severe side effects if the therapeutic window of levofloxacin is not achieved (Boyd et al., 2009; Tamargo et al., 2015). Therefore, if the dose is lower than the standard window, the drug is not effective, and it may increase resistance; on the other hand, if above the MIC range, then it may cause toxicity and adverse reaction (Tamargo et al., 2015). Additionally, levofloxacin is a broad spectrum antibiotic which is susceptible to cause resistance of normal flora; hence, substandard drugs may increase the risk of resistance significantly (Kays et al., 2002; Bastida et al., 2003).

Poor quality antibacterial product may lead to drug resistance, severe side effects, and death; hence, it has a critical role in the treatment and public health (Melo et al., 2014). There are many factors causing resistance, such as irrational and excessive use caused by wrong prescribing and poor quality of medicine (Melo et al., 2014). Table 2 shows the relevant studies reported levofloxacin resistance to $H$. influenza, S. pneumoniae, and $S$. aureus species in different pneumonia. Even though, the site of infections and treatments are different from each other, but it shows levofloxacin resistance have occurred (Ho et al., 2001; Davidson et al., 2002; Kays et al., 2002; Bastida et al., 2003; Endimiani et al., 2005). Thus, it is evident that levofloxacin resistance is one of the main reasons behind treatment failure of pneumonia (Endimiani et al., 2005). Therefore, public awareness about low quality medicine can be created through the reported resistant susceptibility and quality of levofloxacin (Talan et al., 2016).

\section{Dissolution Testing of Levofloxacin Tablets}

Quality control tests used to identify substandard drugs and control the quality of drugs are colorimetric, dissolution, chromatography, and spectrometry procedures (Almuzaini et al., 2013; Maezawa et al., 2013). Dissolution test provides the data of in vitro performance of the drug and prediction for its bioequivalence (Anand et al., 2011). Hence, it is used to estimate the concentration of API and also drug quality (Anand et al., 2011). The dissolution rate consists of drug release by dissolving of solid form in an API into the fluid to determine the stability and physical changes (Kayumba et al., 2004; Nogueira et al.,
2011). Drug dissolution test is an essential factor to identify the quality of drugs especially in oral administration as it provides the process of drug release from its solid formulation, and it can discriminate the substandard and low quality products (Lambert and Conway, 2003; Al Ameri et al., 2012; Khadka et al., 2014).

Dissolution test is required to be applied under in vitro conditions to compare the drug release of active ingredient from a solid form into solution and its bioavailability during a defined time (Frick et al., 1998). Previous studies on dissolution of levofloxacin have shown little variation in levofloxacin tablets tested in different countries. Table 3 shows the various dissolution studies of levofloxacin tablets conducted in various countries.

It is observed that certain generic brands in Japan, Taiwan, Pakistan, and India showed difference in dissolution profile when compared with the innovator product. There is only one study by Bano et al. (2011) comparing few generic brands of levofloxacin tablet does not show significant difference in dissolution profile. The result of this study shows that the different in vitro activity may have a direct effect on the in vivo activities and demonstrate the predictive capability of the former (Sun et al., 2016).

\section{CONCLUSIONS}

Current evidences from various researchers have indicated that poor quality of levofloxacin tablets could be an important factor causing resistance of levofloxacin. Clinical efficacy of this broad spectrum antibiotic relies on the quality of the levofloxacin tablet in term of in vivo release and dissolution inside the gastrointestinal tract. As poor performances of quality control tests of levofloxacin tablets have been reported in developing countries, more PMS to ensure quality of levofloxacin tablets are required to prevent therapy failure and antibiotic resistance.

\section{AUTHOR CONTRIBUTIONS}

RP, SZ and LM conceived the concept; EI, VMR, RP, MS, SZ and LM wrote the initial draft; KBL, AS, NK MM, KSL and GA revised the paper. All authors contributed toward finalizing the manuscript and agreed to be accountable for all aspects of the work. 


\section{REFERENCES}

Abdellah, A., Noordin, M. I., and Wan Ismail, W. A. (2015). Importance and globalization status of good manufacturing practice (GMP) requirements for pharmaceutical excipients. Saudi Pharm. J. 23 (1), 9-13. doi: 10.1016/j. jsps.2013.06.003

Abrahamian, F. M., Deblieux, P. M., Emerman, C. L., Kollef, M. H., Kupersmith, E., Leeper, K. V., Jr., et al. (2008). Health care-associated pneumonia: identification and initial management in the ED. Am. J. Emerg. Med. 26 (6 Suppl), 1-11. doi: 10.1016/j.ajem.2008.03.015

Al Ameri, M. N., Nayuni, N., Anil Kumar, K. G., Perrett, D., Tucker, A., and Johnston, A. (2012). The differences between the branded and generic medicines using solid dosage forms: in-vitro dissolution testing. Results Pharma. Sci. 2, 1-8. doi: 10.1016/j.rinphs.2011.12.001

Almuzaini, T., Choonara, I., and Sammons, H. (2013). Substandard and counterfeit medicines: a systematic review of the literature. BMJ Open 3 (8), e002923. doi: 10.1136/bmjopen-2013-002923

Anand, O., Yu, L. X., Conner, D. P., and Davit, B. M. (2011). Dissolution testing for generic drugs: an FDA perspective. AAPS J. 13 (3), 328-335. doi: 10.1208/ s12248-011-9272-y

Ayukekbong, J. A., Ntemgwa, M., and Atabe, A. N. (2017). The threat of antimicrobial resistance in developing countries: causes and control strategies. Antimicrob. Resist. Infect. Control 6 (1), 47. doi: 10.1186/s13756-017-0208-x

Baldrick, P. (2000). Pharmaceutical excipient development: the need for preclinical guidance. Regul. Toxicol. Pharmacol. 32 (2), 210-218. doi: 10.1006/rtph.2000.1421

Bano, R., Gauhar, S., Naqvi, S. B. S., and Mahmood, S. (2011). Pharmaceutical evaluation of different brands of levofloxacin tablets $(250 \mathrm{mg})$ available in local market of karachi (pakistan). Int. J. Curr. Pharm. Res. 3 (1), 15-22.

Basnet, S., Sharma, A., Mathisen, M., Shrestha, P. S., Ghimire, R. K., Shrestha, D. M., et al. (2015). Predictors of duration and treatment failure of severe pneumonia in hospitalized young nepalese children. PLoS One 10 (3), e0122052. doi: 10.1371/journal.pone.0122052

Bastida, T., Perez-Vazquez, M., Campos, J., Cortes-Lletget, M. C., Roman, F., Tubau, F., et al. (2003). Levofloxacin treatment failure in haemophilus influenzae pneumonia. Emerg. Infect. Dis. 9 (11), 1475-1478. doi: 10.3201/eid0911.030176

Bate, R., Jensen, P., Hess, K., Mooney, L., and Milligan, J. (2013). Substandard and falsified anti-tuberculosis drugs: a preliminary field analysis. Int. J. Tuberc. Lung Dis. 17 (3), 308-311. doi: 10.5588/ijtld.12.0355

Bhavanam, P. R., Lekkala, V. K., Maddirala, P., Reddy, S. N., and Sai Krishna, A. (2011). Formulation and evaluation of levofloxacin using different types and concentrations of superdisintegrants. Pharm. Sci. Res. 100 (5), 1628-1636.

Boyd, L. B., Maynard, M. J., Morgan-Linnell, S. K., Horton, L. B., Sucgang, R., Hamill, R. J., et al. (2009). Relationships among ciprofloxacin, gatifloxacin, levofloxacin, and norfloxacin MICs for fluoroquinolone-resistant escherichia coli clinical isolates. Antimicrob. Agents Chemother. 53 (10), 229-234. doi: 10.1128/AAC.00722-08

Bradley, B. D., Howie, S. R., Chan, T. C., and Cheng, Y. L. (2014). Estimating oxygen needs for childhood pneumonia in developing country health systems: a new model for expecting the unexpected. PLoS One 9 (2), e89872. doi: 10.1371/ journal.pone.0089872

Conway, J., Bero, L., Ondari, C., and Wasan, K. M. (2013). Review of the quality of pediatric medications in developing countries. J. Pharm. Sci. 102 (5), 14191433. doi: $10.1002 /$ jps. 23474

Crispian, S. (2016). "Pneumonia," in Scully's handbook of medical problems in dentistry. (London, United Kingdom: Elsevier Health Sciences), 293.

Currie, C. J., Berni, E., Jenkins-Jones, S., Poole, C. D., Ouwens, M., Driessen, S., et al. (2014). Antibiotic treatment failure in four common infections in UK primary care 1991-2012: longitudinal analysis. BMJ 349, g5493. doi: 10.1136/bmj.g5493

Davidson, R., Cavalcanti, R., Brunton, J. L., Bast, D. J., deAzavedo, J. C. S., Kibsey, P., et al. (2002). Resistance to levofloxacin and failure of treatment of pneumococcal pneumonia. N. Engl. J. Med. 346 (10), 747-750. doi: 10.1056/NEJMoa012122

Davit, B. M., Nwakama, P. E., Buehler, G. J., Conner, D. P., Haidar, S. H., Patel, D. T., et al. (2009). Comparing generic and innovator drugs: a review of 12 years of bioequivalence data from the united states food and drug administration. Ann. Pharmacother. 43 (10), 1583-1597. doi: 10.1345/aph.1M141

Dunne, S., Shannon, B., Dunne, C., and Cullen, W. (2013). A review of the differences and similarities between generic drugs and their originator counterparts, including economic benefits associated with usage of generic medicines, using Ireland as a case study. BMC Pharmacol. Toxicol. 14, 1. doi: 10.1186/2050-6511-14-1

Endimiani, A., Brigante, G., Bettaccini, A. A., Luzzaro, F., Grossi, P., and Toniolo, A. Q. (2005). Failure of levofloxacin treatment in community-acquired pneumococcal pneumonia. BMC Infect. Dis. 5, 106. doi: 10.1186/1471-2334-5-106

Fadeyi, I., Lalani, M., Mailk, N., Van Wyk, A., and Kaur, H. (2015). Quality of the antibiotics-amoxicillin and co-trimoxazole from Ghana, Nigeria, and the United Kingdom. Am. J. Trop. Med. Hyg. 92 (6 Suppl), 87-94. doi: 10.4269/ajtmh.14-0539

Frick, A., Moller, H., and Wirbitzki, E. (1998). Biopharmaceutical characterization of oral immediate release drug products. in vitro/in vivo comparison of phenoxymethylpenicillin potassium, glimepiride and levofloxacin. Eur. J. Pharm. Biopharm. 46 (3), 305-311. doi: 10.1016/S0939-6411(98)00041-1

Gallelli, L., Palleria, C., De Vuono, A., Mumoli, L., Vasapollo, P., Piro, B., et al. (2013). Safety and efficacy of generic drugs with respect to brand formulation. J. Pharmacol. Pharmacother. 4 (Suppl 1), S110-S114. doi: 10.4103/0976-500X.120972

Gibson, L. (2005). Adverse reaction reports may be vulnerable to manipulation. BMJ 330 (7503), 1287. doi: 10.1136/bmj.330.7503.1287

Ho, P. L., Yung, R. W., Tsang, D. N., Que, T. L., Ho, M., Seto, W. H., et al. (2001). Increasing resistance of streptococcus pneumoniae to fluoroquinolones: results of a Hong Kong multicentre study in 2000. J. Antimicrob. Chemother. 48 (5), 659-665. doi: 10.1093/jac/48.5.659

Hosseini, S. A., Darbooy, S., Tehrani Banihashemi, S. A., Naseri, S. M., and Dinarvand, R. (2011). Counterfeit medicines: report of a cross-sectional retrospective study in Iran. Public Health 125 (3), 165-171. doi: 10.1016/j.puhe.2010.11.015

Hu, Y., Mathema, B., Wang, W., Kreiswirth, B., Jiang, W., and Xu, B. (2011). Population-based investigation of fluoroquinolones resistant tuberculosis in rural eastern China. Tuberculosis (Edinb) 91 (3), 238-243. doi: 10.1016/j. tube.2011.03.001

Imran, M., Amjad, A., and Haidri, F. R. (2016). Frequency of hospital acquired pneumonia and its microbiological etiology in medical intensive care unit. Pak. J. Med. Sci. 32 (4), 823-826. doi: 10.12669/pjms.324.8942

Johansson, N., Kalin, M., Tiveljung-Lindell, A., Giske, C. G., and Hedlund, J. (2010). Etiology of community-acquired pneumonia: increased microbiological yield with new diagnostic methods. Clin. Infect. Dis. 50 (2), 202-209. doi: 10.1086/648678

Karunamoorthi, K. (2014). The counterfeit anti-malarial is a crime against humanity: a systematic review of the scientific evidence. Malar. J. 13, 209. doi: 10.1186/1475-2875-13-209

Kaul, S., Zimmer, J., Dehus, O., Costanzo, A., Daas, A., Buchheit, K. H., et al. (2016). Standardization of allergen products: 3. validation of candidate european pharmacopoeia standard methods for quantification of major birch allergen bet v 1. Allergy. 7 (10), 1414-1424. doi: 10.1111/all.12898

Kays, M. B., Smith, D. W., Wack, M. E., and Denys, G. A. (2002). Levofloxacin treatment failure in a patient with fluoroquinolone-resistant Streptococcus pneumoniae pneumonia. Pharmacother. 22 (3), 395-399. doi: 10.1592/phco.22.5.395.33185

Kayumba, P. C., Risha, P. G., Shewiyo, D., Msami, A., Masuki, G., Ameye, D., et al. (2004). The quality of essential antimicrobial and antimalarial drugs marketed in Rwanda and Tanzania: influence of tropical storage conditions on in vitro dissolution. J. Clin. Pharm. Ther. 29 (4), 331-338. doi: 10.1111/j.1365-2710.2004.00568.x

Kesselheim, A. S., Misono, A. S., Lee, J. L., Stedman, M. R., Brookhart, M. A., Choudhry, N. K., et al. (2008). Clinical equivalence of generic and brand-name drugs used in cardiovascular disease: a systematic review and meta-analysis. JAMA 300 (21), 2514-2526. doi: 10.1001/jama.2008.758

Khadka, P., Ro, J., Kim, H., Kim, I., Kim, J.T., Kim, H., et al. (2014). Pharmaceutical particle technologies: an approach to improve drug solubility, dissolution and bioavailability. Asian J. Pharm. Sci. 9 (6), 304-316. doi: 10.1016/j.ajps.2014.05.005

Khasawneh, F. A., Karim, A., Mahmood, T., Ahmed, S., Jaffri, S. F., Tate, M. E., et al. (2014). Antibiotic de-escalation in bacteremic urinary tract infections: potential opportunities and effect on outcome. Infect. 42 (5), 829-834. doi: 10.1007/s15010-014-0639-8

Khurelbat, D., Dorj, G., Bayarsaikhan, E., Chimedsuren, M., Sanjjav, T., Morimoto, T. et al. (2014). Prevalence estimates of substandard drugs in Mongolia using a random sample survey. Springerplus 3, 709. doi: 10.1186/2193-1801-3-709

Lalani, M., Kaur, H., Mohammed, N., Mailk, N., van Wyk, A., Jan, S., et al. (2015). Substandard antimalarials available in Afghanistan: a case for assessing the quality of drugs in resource poor settings. Am. J. Trop. Med. Hyg. 92 (6 Suppl), 51-58. doi: 10.4269/ajtmh.14-0394 
Lambert, P. A., and Conway, B. R. (2003). Pharmaceutical quality of ceftriaxone generic drug products compared with rocephin. J. Chemother. 15 (4), 357-368. doi: 10.1179/joc.2003.15.4.357

Lee, M. T., Lee, S. H., Chang, S. S., Chan, Y. L., Pang, L., Hsu, S. M., et al. (2015). Comparative treatment failure rates of respiratory fluoroquinolones or betalactam + macrolide versus beta-lactam alone in the treatment for communityacquired pneumonia in adult outpatients: an analysis of a nationally representative claims database. Medicine (Baltimore) 94 (39), 1-8. doi: 10.1097/ MD.0000000000001662

Leekha, S., Terrell, C. L., and Edson, R. S. (2011). General principles of antimicrobial therapy. Mayo Clin. Proc. 86 (2), 156-167. doi: 10.4065/mcp.2010.0639

Li, T. W., Tu, P. W., Liu, L. L., and Wu, S. I. (2015). Assurance of medical device quality with quality management system: an analysis of good manufacturing practice implementation in Taiwan. Biomed Res. Int. 2015, 670420. doi: 10.1155/2015/670420

Liu, W. K., Liu, Q., Chen, D. H., Liang, H. X., Chen, X. K., Chen, M. X., et al. (2014). Epidemiology of acute respiratory infections in children in Guangzhou: a three-year study. PLoS One 9 (5), e96674. doi: 10.1371/journal.pone.0096674

Losada-Urzáiz, F., González-Gaya, C., and Sebastián-Pérez, M.A.(2015). Metrological regulations for quality control equipment calibration in pharmaceutical industry. Procedia Eng. 132 (2), 811-815. doi: 10.1016/j.proeng.2015.12.564

Maezawa, K., Yajima, R., Terajima, T., Kizu, J., and Hori, S. (2013). Dissolution profile of 24 levofloxacin (100 mg) tablets. J. Infect. Chemother. 19 (5), 996-998. doi: 10.1007/s10156-012-0530-4

Mandell, L. A., Wunderink, R. G., Anzueto, A., Bartlett, J. G., Campbell, G. D., Dean, N. C., et al. (2007). Infectious diseases society of america/ american thoracic society consensus guidelines on the management of community-acquired pneumonia in adults. Clin. Infect. Dis. 44 (2), 27-72. doi: $10.1086 / 511159$

Melo, V. V., Costa, M. S., and Soares, A. Q. (2014). Quality of prescription of highalert medication and patient safety in pediatric emergency. Farm. Hosp. 38 (1), 9-17. doi: 10.7399/FH.2014.38.1.1097

Miller, R. A., Walker, R. D., Carson, J., Coles, M., Coyne, R., Dalsgaard, I., et al. (2005). Standardization of a broth microdilution susceptibility testing method to determine minimum inhibitory concentrations of aquatic bacteria. Dis. Aquat. Organ. 64 (3), 211-222. doi: 10.3354/dao064211

Nazir, S. U. R., Nadeem, M., Malik, A., Irshad, K. N., Amer, M., and Asjad, H. M. (2013). Formulation and in-vitro evaluation of levofloxacin tablets by using superdisintegrants. Am. J. Res. Commun. 1 (4), 193-199.

Newton, P. N., Green, M. D., and Fernandez, F. M. (2010). Impact of poor-quality medicines in the 'developing' world. Trends Pharmacol. Sci. 31 (3), 99-101. doi: 10.1016/j.tips.2009.11.005

Nightingale, C. H. (2005). A survey of the quality of generic clarithromycin products from 18 countries. Clin. Drug Investig. 25 (2), 135-152. doi: 10.2165/00044011-200525020-00006

Nitzki-George, D. (2004). "Getting the terminology straight," in Generic Alternatives to Prescription Drugs. Ed. C. Rosenberf (North Bergen: Basic Health Publication), 5.

Nogueira, F. H., Moreira-Campos, L. M., Santos, R. L., and Pianetti, G. A. (2011). Quality of essential drugs in tropical countries: evaluation of antimalarial drugs in the brazilian health system. Rev. Soc. Bras. Med. Trop. 44 (5), 582-586. doi: 10.1590/S0037-86822011000500010

Noreddin, A. M., and Elkhatib, W. F. (2010). Levofloxacin in the treatment of community-acquired pneumonia. Expert Rev. Anti Infect. Ther. 8 (5), 505-514. doi: $10.1586 /$ eri.10.35

Nsimba, S. E. (2008). Problems associated with substandard and counterfeit drugs in developing countries: a review article on global implications of counterfeit drugs in the era of antiretroviral (ARVs) drugs in a free market economy. East Afr. J. Public Health 5 (3), 205-210. doi: 10.4314/eajph.v5i3.39004

Panchagnula, R., Kumar Bajpai, A., Agrawal, S., and Ashokraj, Y. (2006). Dissolution testing of marketed rifampicin containing fixed dose combination formulations using a new discriminative media: a post marketing retrospective study. Pharmazie 61 (10), 851-854.

Paveliu, M. S., Bengea, S., and Paveliu, F. S. (2011). Generic substitution issues: brandgeneric substitution, generic-generic substitution, and generic substitution of narrow therapeutic index (NTI)/critical dose drugs. Maedica (Buchar) 6 (1), 52-58.

Rizvi, M., Nisa, Z. U., Ahmed, M., Naqvi, B., Abbas, A., and Sabah, A. (2014). Comparision of in vitro antibacterial activity of cefoperazone and levofloxacin against different clinical isolates. Int. J. Allied Med. Sci. Clin. Res. 2 (1), 74-78.
Sahm, D. F., Peterson, D. E., Critchley, I. A., and Thornsberry, C. (2000). Analysis of ciprofloxacin activity against streptococcus pneumoniae after 10 years of use in the United States. Antimicrob. Agents Chemother. 44 (9), 2521-2524. doi: 10.1128/AAC.44.9.2521-2524.2000

Sánchez García, M. (2009). Early antibiotic treatment failure. Int. J. Antimicrob. Agents 34 (3), 14-19. doi: 10.1016/S0924-8579(09)70552-7

Sarpong, E. M., and Miller, G. E. (2014). Narrow- and broad-spectrum antibiotic use among U.S. children. Health Serv. Res. 50 (3), 830-846. doi: 10.1111/1475-6773.12260

Seok, H., Kang, C. I., Huh, K., Cho, S. Y., Ha, Y. E., Chung, D. R., et al. (2018). Risk factors for community-onset pneumonia caused by levofloxacinnonsusceptible streptococcus pneumoniae. Microb. Drug Resist. doi: 10.1089/ mdr.2017.0416

Scoper, S. V. (2008). Review of third-and fourth-generation fluoroquinolones in ophthalmology: in-vitro and in-vivo efficacy. Adv. Ther. 25 (10), 979-994. doi: 10.1007/s12325-008-0107-X

Sun, H. Y., Liao, H. W., Sheng, M. H., Tai, H. M., Kuo, C. H., and Sheng, W. H. (2016). Bioequivalence and in vitro antimicrobial activity between generic and brand-name levofloxacin. Diagn. Microbiol. Infect. Dis. 85 (3), 347-351. doi: 10.1016/j.diagmicrobio.2016.04.015

Talan, D. A., Takhar, S. S., Krishnadasan, A., Abrahamian, F. M., Mower, W. R., Moran, G. J., et al. (2016). Fluoroquinolone-resistant and extended-spectrum betalactamase-producing escherichia coli infections in patients with pyelonephritis, United States. Emerg. Infect. Dis. 22 (9), 1594-1603. doi: 10.3201/eid2209.160148

Tamargo, J., LeHeuzey, J. Y., and Mabo, P. (2015). Narrow therapeutic index drugs: a clinical pharmacological consideration to flecainide. Eur. J. Clin. Pharmacol. 71 (5), 549-567. doi: 10.1007/s00228-015-1832-0

Taylor, R. B., Shakoor, O., Behrens, R. H., Everard, M., Low, A. S., Wangboonskul, J., et al. (2001). Pharmacopoeial quality of drugs supplied by Nigerian pharmacies. Lancet 357 (9272), 1933-1936. doi: 10.1016/S0140-6736(00)05065-0

Tipke, M., Diallo, S., Coulibaly, B., Storzinger, D., Hoppe-Tichy, T., Sie, A., et al. (2008). Substandard anti-malarial drugs in Burkina Faso. Malar. J. 7, 95. doi: 10.1186/1475-2875-7-95

Tomic, S., Filipovic Sucic, A., and Ilic Martinac, A. (2010). Good manufacturing practice: the role of local manufacturers and competent authorities. Arh. Hig. Rada Toksikol. 61 (4), 425-436. doi: 10.2478/10004-1254-61-2010-2035

Torloni, M. R., Gomes Freitas, C., Kartoglu, U. H., Metin Gulmezoglu, A., and Widmer, M. (2016). Quality of oxytocin available in low- and middleincome countries: a systematic review of the literature. BJOG. 123 (13), 2076-2208 doi: 10.1111/1471-0528.13998

Wang, T., Hoag, S. W., Eng, M. L., Polli, J., and Pandit, N. (2015). Quality of antiretroviral and opportunistic infection medications dispensed from developing countries and internet pharmacies. J. Clin. Pharm. Ther. 40 (1), 68-75. doi: $10.1111 /$ jcpt.12226

World Health Organization. (2011). Definition of active pharmaceutical ingredient. Geneva: WHO.

World Health Organization. (2016). Substandard, spurious, falsely labelled, falsified and counterfeit (SSFFC) medical products. Stockholm: World Health Organization. Retrieved from http://www.who.int/mediacentre/factsheets/fs275/en/\#.

Zaid, A. N., Al-Ramahi, R. J., Ghoush, A. A., Qaddumi, A., and Zaaror, Y. A., (2013). Weight and content uniformity of lorazepam half-tablets: a study of correlation of a low drug content product. Saudi Pharm. J. 21 (1), 71-75. doi: 10.1016/j.jsps.2011.12.009

Zavras, D., Zavras, A. I., Kyriopoulos, I. I., and Kyriopoulos, J. (2016). Economic crisis, austerity and unmet healthcare needs: the case of Greece. BMC Health Serv. Res. 16 (1), 309. doi: 10.1186/s12913-016-1557-5

Conflict of Interest Statement: The authors declare that the research was conducted in the absence of any commercial or financial relationships that could be construed as a potential conflict of interest.

Copyright (C) 2019 Izadi, Afshan, Patel, Rao, Liew, Meor Mohd Affandi, Kifli, Suleiman, Lee, Sarker, Zaidi and Ming. This is an open-access article distributed under the terms of the Creative Commons Attribution License (CCBY). The use, distribution or reproduction in other forums is permitted, provided the original author(s) and the copyright owner(s) are credited and that the original publication in this journal is cited, in accordance with accepted academic practice. No use, distribution or reproduction is permitted which does not comply with these terms. 